\title{
Removal of Aluminum on Glass Substrate by Atmospheric-Pressure Plasma Jet Irradiation
}

\author{
Hiroshi Kuwahata* and Takeshi Yamaguchi \\ Department of Electrical and Electronic Engineering, School of Engineering, \\ Tokai University, 4-1-1 Kitakaname, Hiratsuka, Kanagawa 259-1292, Japan \\ (Received 2 November 2016; Accepted 29 November 2016; Published 24 December 2016)
}

\begin{abstract}
An atmospheric-pressure argon (Ar) plasma jet was generated with a frequency of $10 \mathrm{kHz}$, an applied voltage of $10 \mathrm{kV}$, and an Ar gas flow rate of $10 \mathrm{~L} / \mathrm{min}$. When an aluminum (Al) thin film deposited on a glass substrate was irradiated with the Ar plasma jet in air for $5 \mathrm{~s}, \mathrm{Al}$ was removed. The removal rate was $\sim 700 \mathrm{~nm} / \mathrm{s}$. Because the streamers in the plasma reached the $\mathrm{Al}$ thin film, $\mathrm{Al}$ was removed and a mark was formed on the film, which was referred to as a removal mark. The shape of the removal mark depended on the irradiation distance: it was ring-shaped with an inner diameter of $\sim 5 \mathrm{~mm}$ and an outer diameter of $\sim 6 \mathrm{~mm}$ for irradiation distances of $2-7$ $\mathrm{mm}$, and disc-shaped with a diameter of $\sim 5 \mathrm{~mm}$ for irradiation distances of 10-20 $\mathrm{mm}$. The dependence of the shape of the removal mark on the irradiation distance suggests that the distribution of the streamers in the plasma depended on the irradiation distance. The streamers inside the quartz tube were concentrated along the inner wall. In contrast, the streamers outside the tube were distributed in a ring shape with an inner diameter of $\sim 5 \mathrm{~mm}$ and an outer diameter of $\sim 6 \mathrm{~mm}$ for irradiation distances of $2-7 \mathrm{~mm}$, but they converged then diverged to form a smaller disc shape with a diameter of $\sim 5 \mathrm{~mm}$ for irradiation distances of 10-20 mm. [DOI: 10.1380/ejssnt.2016.231]
\end{abstract}

Keywords: Plasma processing; Aluminum; Glass surfaces; Laser microscope

\section{INTRODUCTION}

Research on surface modification using atmosphericpressure plasma has been carried out for various materials, such as metals [1-3], glass [4-7], semiconductors [8, 9], and polymers [10-12]. Most of such research has focused on cleaning the surface of the materials and improving the hydrophilicity of the surface. Yamamoto et al. irradiated an aluminum $(\mathrm{Al})$ surface with atmospheric-pressure oxygen/argon $\left(\mathrm{O}_{2} / \mathrm{Ar}\right)$ plasma and measured the contact angle of water on the surface. They reported that the contact angle decreased and that the hydrophilicity of the surface increased [1]. Kim et al. irradiated an Al surface with an atmospheric-pressure nitrogen/oxygen $\left(\mathrm{N}_{2} / \mathrm{O}_{2}\right)$ plasma jet and measured the contact angle of water. They reported that the contact angle decreased from 66.1 to $19.6^{\circ}$ by plasma jet irradiation, demonstrating the improved hydrophilicity of the surface. In the X-ray photoelectron spectroscopy (XPS) spectra, they found that the intensity of a peak corresponding to carbon (C) decreased, while that corresponding to oxygen $(\mathrm{O})$ increased [2].

In our previous studies, quartz glass was irradiated for $5 \mathrm{~s}$ with an atmospheric-pressure Ar plasma jet generated with an applied voltage of $10 \mathrm{kV}$ and an Ar gas flow rate of $10 \mathrm{~L} / \mathrm{min}$. As a result, the contact angle of water on the glass surface decreased from 70 to $10^{\circ}$, showing that the quartz glass surface became superhydrophilic [13]. From the XPS results, we considered that the quartz glass surface became superhydrophilic because the hydrophobic organic compounds that adsorbed onto the surface were removed by plasma jet irradiation. When a silicon (Si) surface was irradiated with the above-mentioned $\mathrm{Ar}$ plasma jet for $5 \mathrm{~s}$, the contact angle of water decreased from 77 to $7^{\circ}$, revealing that the Si surface became superhydrophilic [14]. From the results of time-of-flight secondary ion mass spectroscopy (TOF-SIMS), we concluded that the Si surface became superhydrophilic because the

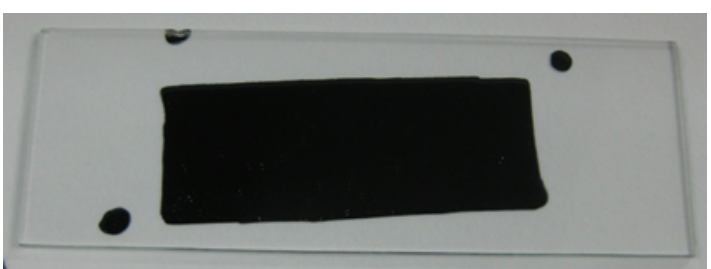

FIG. 1. Photograph of Al thin film fabricated on glass substrate by vacuum deposition.

hydrophobic polydimethylsiloxane (PDMS) [15-17] that adsorbed onto the Si surface was removed by the plasma, and the number of hydrophilic silanol $(\mathrm{SiOH})$ groups on the Si surface increased.

Other reports show that in a vacuum, $\mathrm{Al}$ is removed by reactive plasma etching using chlorine-based gases, such as boron trichloride $\left(\mathrm{BCl}_{3}\right)$, carbon tetrachloride $\left(\mathrm{CCl}_{4}\right)$, and silicon tetrachloride $\left(\mathrm{SiCl}_{4}\right)[18-22]$.

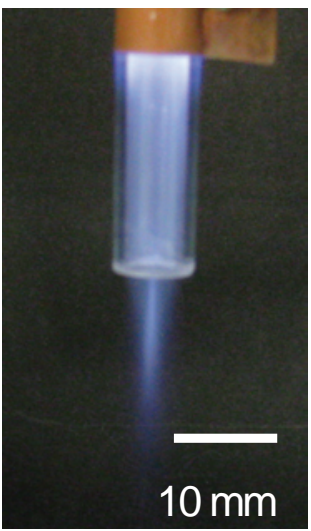

FIG. 2. Photograph of Ar plasma jet ejected into air. 


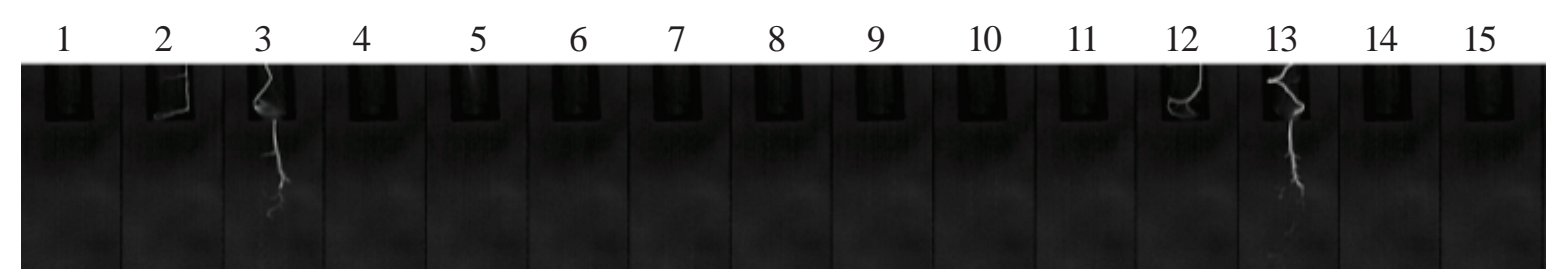

FIG. 3. Images of Ar plasma jet ejected into air obtained using high-speed camera.

Thus far, an increase in the hydrophilicity of Al surfaces by atmospheric-pressure plasma and the removal of $\mathrm{Al}$ by plasma etching in vacuum have been reported. However, the removal of $\mathrm{Al}$ by etching using atmosphericpressure plasma has not yet been reported, to the best of our knowledge.

If our atmospheric-pressure Ar plasma jet can be used to etch $\mathrm{Al}$ in air, chlorine-based gas will not be required and safe etching will be possible. Moreover, cost reduction will be achieved because neither treatment of the discharged gas nor vacuum equipment will be necessary. As a result, atmospheric-pressure Ar plasma jet irradiation is expected to be used as a new $\mathrm{Al}$ processing technique.

In this paper, we investigated whether $\mathrm{Al}$ is etched when an Al-deposited thin film on a glass substrate is irradiated with an atmospheric-pressure Ar plasma jet in air. In addition, the changes in the etching pattern were examined when the irradiation distance was varied.

\section{EXPERIMENT}

In the unit to generate a plasma jet, a copper tube (inner diameter, $4 \mathrm{~mm}$; outer diameter, $6 \mathrm{~mm}$ ) as the discharge electrode was inserted into a dielectric quartz tube (length, $50 \mathrm{~mm}$; inner diameter, $6 \mathrm{~mm}$; outer diameter, 8 $\mathrm{mm}$ ) around which copper foil (thickness, $0.05 \mathrm{~mm}$; width, $10 \mathrm{~mm}$ ) was wrapped as the ground electrode [23, 24]. A high $\mathrm{AC}$ voltage was applied to induce dielectric barrier discharge inside the quartz tube between the electrodes and to convert the introduced Ar gas to plasma, which was ejected into air in the form of a jet. A high-voltage power supply (LHV-10AC, Logy Electric Co., Ltd.) was used to generate an Ar plasma jet (frequency, $10 \mathrm{kHz}$; applied voltage, $10 \mathrm{kV}$; and Ar gas flow rate, $10 \mathrm{~L} / \mathrm{min}$ ). The Al thin film was irradiated with the Ar plasma jet for 5 s. The distance from the end of the quartz tube to the $\mathrm{Al}$ thin film (irradiation distance) was in the range of 2-30 $\mathrm{mm}$. The voltage and current were measured using a highvoltage probe (P6015A, Tektronix, Inc.) and a current probe (A621, Tektronix, Inc.), respectively, connected to a digital oscilloscope (TDS1001B, Tektronix, Inc.). The gas flow rate was adjusted using a gas flowmeter (RK1250, Kofloc Kyoto, Kojima Instruments Inc.). The Al thin film was formed on a glass substrate $(76 \times 26 \times 1.2$ $\mathrm{mm}^{3}$ ) using a vacuum deposition system. Figure 1 shows a photograph of the $\mathrm{Al}$ thin film fabricated on the glass substrate by vacuum deposition. The Al thin film has an area of $\sim 40 \times 16 \mathrm{~mm}^{2}$ and a thickness of $\sim 3.5 \mu \mathrm{m}$. After plasma jet irradiation, the surface of the Al thin film was observed using a laser microscope VK-X200 (Keyence
Corporation). A high-speed camera (FASTCAM SA-Z, Photron Limited) was used to take photographs of the $\mathrm{Al}$ thin film at 100,000 fps. The surface temperature of the $\mathrm{Al}$ thin film during plasma jet irradiation was measured using a thermometer (Thermo Shot F30, Nippon Avionics Co., Ltd.).

\section{RESULTS AND DISCUSSION}

Figure 2 shows a photograph of an Ar plasma jet ejected into air. The Ar plasma jet was ejected from the end of the quartz tube into air, extended $\sim 20 \mathrm{~mm}$, and had a maximum diameter of $6 \mathrm{~mm}$.

Figure 3 shows high-speed camera images of the Ar plasma jet ejected into air. These 15 images were continuously obtained at intervals of $0.01 \mathrm{~ms}$. The streamers extended outside the quartz tube, as shown in the third frame, and did so again in the 13th frame. The interval between the two frames $(0.1 \mathrm{~ms})$ was equal to the period of $\mathrm{AC}$ with a frequency of $10 \mathrm{kHz}$. This result indicates that the streamer discharge occurred at a rate of 10,000 times per second in the Ar plasma jet.

Figure 4 shows photographs of the Ar plasma jet for different irradiation distances (upper figures) and those of the Al thin film obtained after plasma jet irradiation (lower figures). For an irradiation distance of $30 \mathrm{~mm}$ [Fig. 4(a)], the plasma jet seemed not to reach the $\mathrm{Al}$ thin film. For irradiation distances of $\leq 20 \mathrm{~mm}$ [Figs. 4(b) $4(\mathrm{~g})]$, the plasma jet reached the $\mathrm{Al}$ thin film, and many streamers were observed in the quartz tube. For irradiation distances of 20 and $15 \mathrm{~mm}$ [Figs. 4(b) and 4(c)], the streamers were converged at the end of the quartz tube and appeared to reach the $\mathrm{Al}$ thin film. The diameters of the plasma reaching the Al thin film were $\sim 5$ and $\sim 6 \mathrm{~mm}$. For irradiation distances of $\leq 10 \mathrm{~mm}$ [Figs. $4(\mathrm{~d})-4(\mathrm{~g})]$, the streamers in the quartz tube appeared to directly reach the $\mathrm{Al}$ thin film without convergence. The diameter of the plasma reaching the $\mathrm{Al}$ thin film was $\sim 6 \mathrm{~mm}$ for an irradiation distance of $10 \mathrm{~mm}$ [Fig. 4(d)]. It was $\sim 7 \mathrm{~mm}$ for other irradiation distances [Figs. 4(e)- 4(g)]. This was slightly larger than the inner diameter of the quartz tube $(6 \mathrm{~mm})$. These results indicate that the plasma jet did not reach the $\mathrm{Al}$ thin film for an irradiation distance of $30 \mathrm{~mm}$ [Fig. 4(a)] but reached the film for irradiation distances of $\leq 20 \mathrm{~mm}$ [Figs. $4(\mathrm{~b})-4(\mathrm{~g})$ ]. It was also found that the streamers were not observed when the plasma jet did not reach the $\mathrm{Al}$ thin film but were observed when the plasma jet reached the Al thin film.

For an irradiation distance of $30 \mathrm{~mm}$ [Fig. 4(h)], the plasma jet did not reach the $\mathrm{Al}$ thin film and no change 


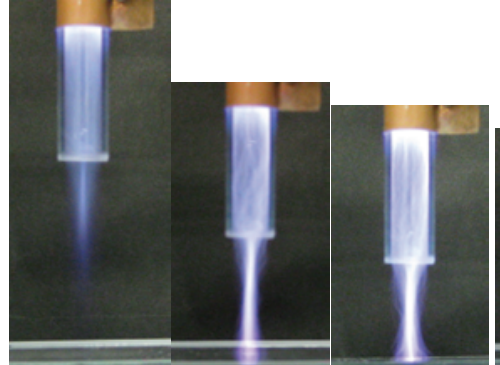

(a)

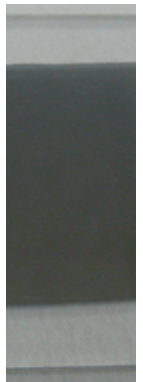

(h) (b)

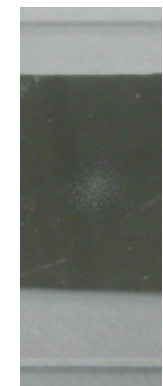

(i) (c)

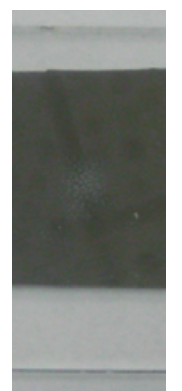

(j)

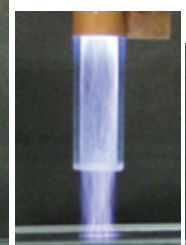

(d)

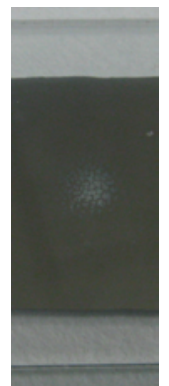

(k)

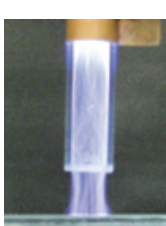

(e)

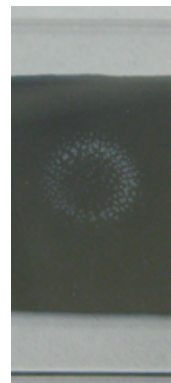

(1)

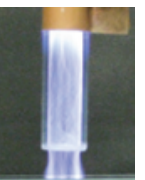

(f)

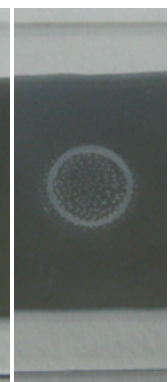

(m)

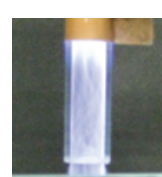

(g)

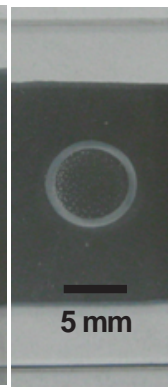

(n)

FIG. 4. Photographs of plasma jet and $\mathrm{Al}$ thin film obtained after plasma jet irradiation for different irradiation distances: (a, h) $30 \mathrm{~mm},(\mathrm{~b}, \mathrm{i}) 20 \mathrm{~mm},(\mathrm{c}, \mathrm{j}) 15 \mathrm{~mm},(\mathrm{~d}, \mathrm{k}) 10 \mathrm{~mm}$, (e, l) $7 \mathrm{~mm}$, (f, m) $5 \mathrm{~mm}$, and (g, n) $2 \mathrm{~mm}$.

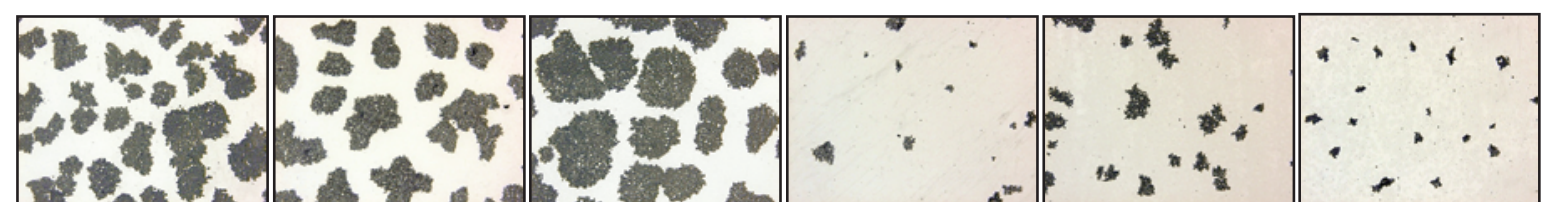

(a)

(b)

(c)

(d)

(e)

(f)

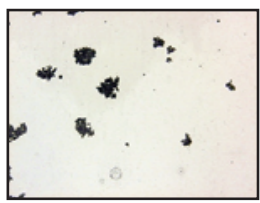

(g)

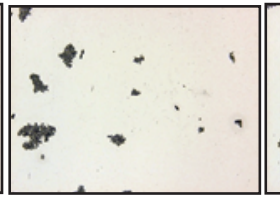

(h)

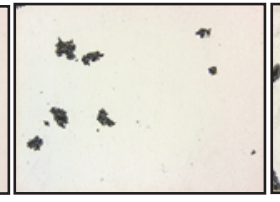

(i)

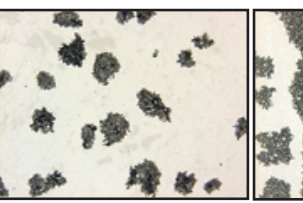

(j)

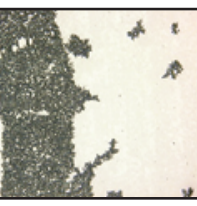

(k)

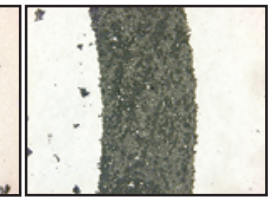

(l)

FIG. 5. Laser microscopy images of center of irradiation spot (upper figures) and groove of ring (lower figures) for different irradiation distances: (a, g) $20 \mathrm{~mm},(\mathrm{~b}, \mathrm{~h}) 15 \mathrm{~mm},(\mathrm{c}, \mathrm{i}) 10 \mathrm{~mm},(\mathrm{~d}, \mathrm{j}) 7 \mathrm{~mm},(\mathrm{e}, \mathrm{k}) 5 \mathrm{~mm}$, and (f, l) $2 \mathrm{~mm}$.

was observed on the film. For an irradiation distance of $20 \mathrm{~mm}$ [Fig. 4(i)], the plasma jet started reaching the $\mathrm{Al}$ thin film, and many small dots were distributed in a disc shape on the irradiated region of the Al thin film. The diameter of this disc was $\sim 5 \mathrm{~mm}$. For irradiation distances of 15 and $10 \mathrm{~mm}$ [Figs. 4(j) and 4(k)], many small dots were distributed similarly in a disc shape. The diameters of the discs were $\sim 6$ and $\sim 7 \mathrm{~mm}$, respectively. For an irradiation distance of $7 \mathrm{~mm}$ [Fig. 4(1)], many small dots were distributed in a ring shape. The inner and outer diameters of the ring were $\sim 6$ and $\sim 8 \mathrm{~mm}$, respectively. For an irradiation distance of $5 \mathrm{~mm}$ [Fig. 4(m)], the ring was distinct and many small dots were also observed inside the ring. The inner and outer diameters of the ring were $\sim 6$ and $\sim 8 \mathrm{~mm}$, respectively. For an irradiation distance of $2 \mathrm{~mm}$ [Fig. $4(\mathrm{n})$ ], the ring was more distinct, but the small dots inside the ring were blurred. The inner and outer diameters of the ring were $\sim 6$ and $\sim 8 \mathrm{~mm}$, respectively. The sizes of the discs and rings on the $\mathrm{Al}$ thin film were the same as those of the regions irradiated with the plasma jet. This result indicates that the pattern observed on the Al thin film after plasma jet irradiation was formed by the streamers reaching the film. On the mark where the streamers reached, the glass substrate was exposed and $\mathrm{Al}$ disappeared, indicating that $\mathrm{Al}$ was removed by the streamer discharge.

The above results indicate that the streamers in the plasma were not uniformly distributed but were concentrated along the inner wall of the quartz tube. When the irradiation distance was short, the streamers flowed along the inner wall of the quartz tube and reached the Al thin film. When the irradiation distance was long, the 


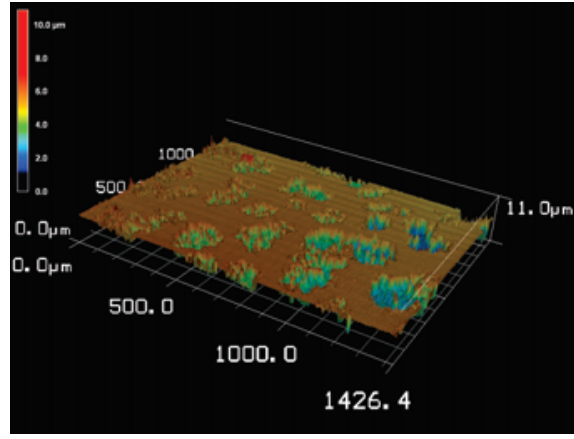

(a)

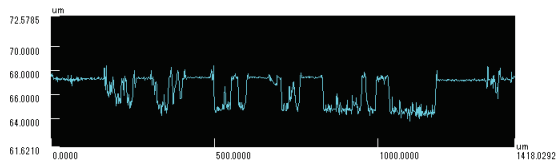

(e)

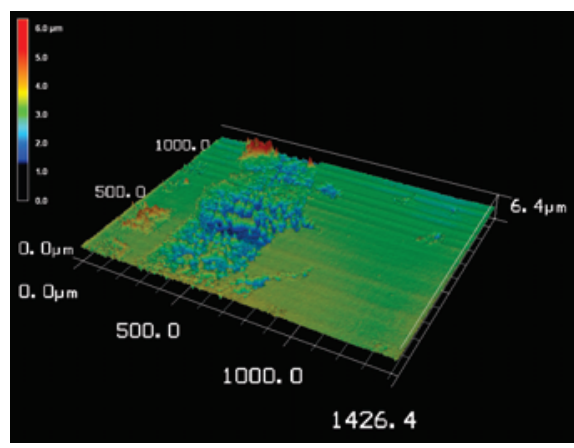

(c)

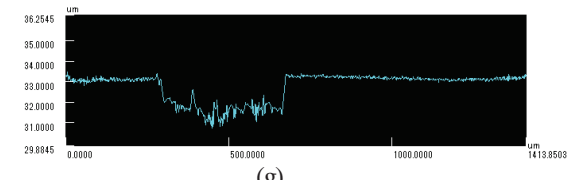

(g)

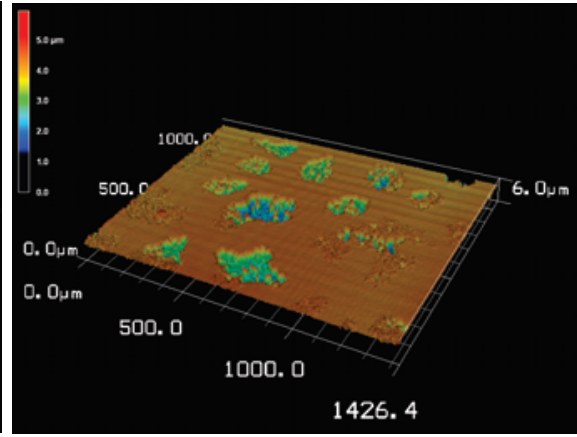

(b)

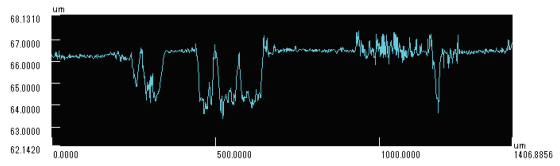

(f)

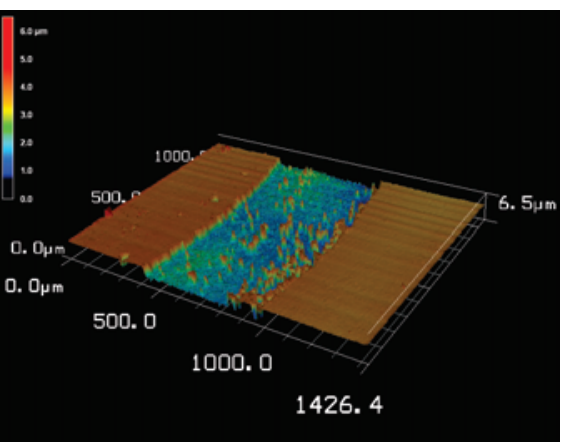

(d)

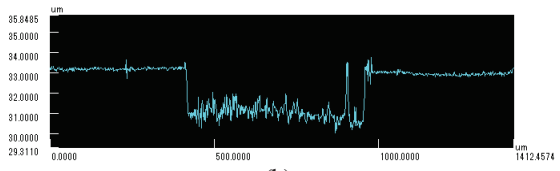

(h)

FIG. 6. 3D laser microscopy images and cross-sectional images of center of irradiation spot at irradiation distances of (a) 20 $\mathrm{mm}$ and (b) $15 \mathrm{~mm}$ and groove of ring at irradiation distances of (c) $5 \mathrm{~mm}$ and (d) $2 \mathrm{~mm}$.

streamers flowed along the inner wall of the quartz tube, converged at the end of the tube, and then reached the Al thin film.

Observation using the high-speed camera revealed that the streamer discharge occurred at a rate of 10,000 times per second. That is, during $5 \mathrm{~s}$ of plasma jet irradiation, the streamers reached the surface of the Al thin film 50,000 times. The removal mark was distinct for short irradiation distances, whereas it was blurred for long irradiation distances. This was thought to be because the streamers reached the $\mathrm{Al}$ thin film 50,000 times for short irradiation distances, whereas they reached the $\mathrm{Al}$ thin film less than 50,000 times for long irradiation distances.

Figure 5 shows laser microscopy images of the center of the irradiation spot (upper figures) and the groove of the ring (lower figures). The image size was $1000 \times$ $1460 \mu \mathrm{m}^{2}$. The white regions represent the presence of $\mathrm{Al}$, whereas the grey regions represent the absence of $\mathrm{Al}$. All images have grey regions, confirming that $\mathrm{Al}$ was removed when the plasma jet reached the Al thin film (that is, for all irradiation distances of $\leq 20 \mathrm{~mm}$ ) [Figs. 5(a)$5(\mathrm{f})]$. No regularity was found in the shape of the removal marks: they were largest for an irradiation distance of $10 \mathrm{~mm}$ [Fig. 5(c)] and decreased with decreasing irradiation distance. It was considered that the small removal marks were attributed to the smaller number of reaches of the streamers, whereas the large removal marks were attributed to the greater number of reaches of the streamers.

For irradiation distances of $\leq 7 \mathrm{~mm}$ [Figs. $5(\mathrm{j})-5(\mathrm{l})]$, the area and size of the removal marks increased with decreasing irradiation distance, and they formed a ring-shaped groove, which became more distinct and wider. No regularity was found in the shape of the removal marks. From Fig. 5, the distribution of the streamers in the plasma was not uniform but dependent on the irradiation distance. It was confirmed that the streamers flowed along the inner wall of the quartz tube to reach the $\mathrm{Al}$ thin film for short irradiation distances, whereas they flowed along the inner wall of the quartz tube, converged at the end of the tube, and then reached the $\mathrm{Al}$ thin film for long irradiation distances.

Figure 6 shows 3D images obtained from laser microscopy and their cross-sectional images. The size of 

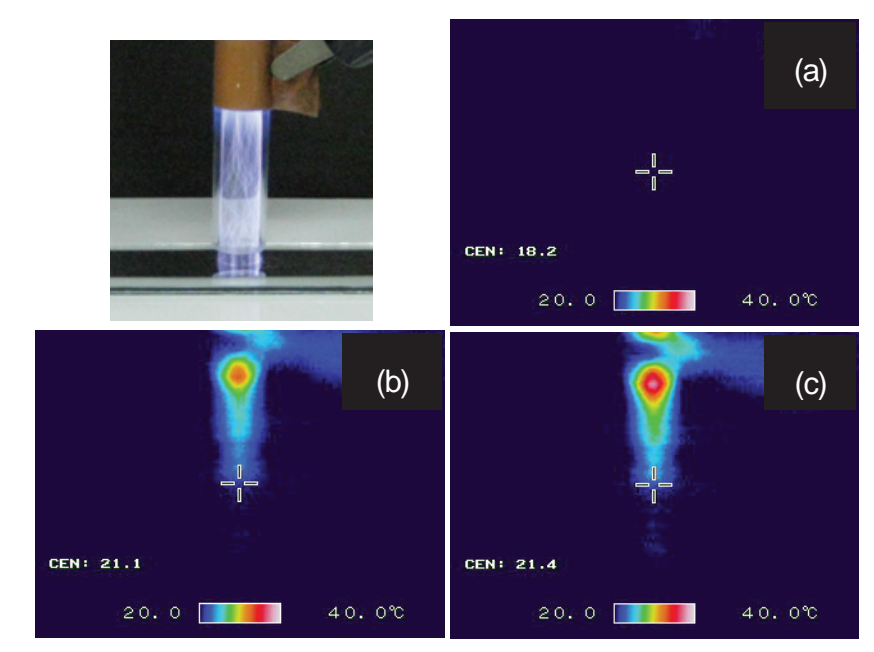

FIG. 7. Thermography images of Al thin film during Ar plasma jet irradiation at irradiation distance of $2 \mathrm{~mm}$ : (a) before irradiation, (b) $1 \mathrm{~s}$ of irradiation, and (c) $5 \mathrm{~s}$ of irradiation.

the $3 \mathrm{D}$ images was the same as that in Fig. 5. The grey regions observed in Fig. 5 are shown in blue in Figs. 6(a)$6(\mathrm{~d})$, to indicate that the height of the regions was smaller than that of the surface of the Al thin film. This indicates that $\mathrm{Al}$ was removed from the regions. In addition, red regions were observed in Figs. 6(a)-6(d), showing that regions taller than the surface of the $\mathrm{Al}$ thin film were also generated. The red regions were considered to be generated when the removed $\mathrm{Al}$ was splattered and deposited on the regions.

The etching depths determined from the cross-sectional images were $\sim 2.5 \mu \mathrm{m}$ in Fig. 6(e), $\sim 3.0 \mu \mathrm{m}$ in Fig. 6(f), $\sim 2.0 \mu \mathrm{m}$ in Fig. $6(\mathrm{~g})$, and $\sim 3.5 \mu \mathrm{m}$ in Fig. 6(h). Therefore, our etching rate was at least $\sim 700 \mathrm{~nm} / \mathrm{s}$ in the depth direction. The width of the groove of the ring in Fig. 6(h) was $\sim 558 \mu \mathrm{m}$. In the fabrication process of semiconductor devices, reactive plasma etching using a chlorine-based gas in vacuum is adopted to remove $\mathrm{Al}$. The reported $\mathrm{Al}$ etching rates were $0.83 \mathrm{~nm} / \mathrm{s}$ [18], $1.0 \mathrm{~nm} / \mathrm{s}$ [22], and 1.9 $\mathrm{nm} / \mathrm{s}$ [21] for $\mathrm{BCl}_{3}, 8.3 \mathrm{~nm} / \mathrm{s}$ [19], $6 \mathrm{~nm} / \mathrm{s}$ [20], and 5.5 $\mathrm{nm} / \mathrm{s}$ [21] for $\mathrm{CCl}_{4}$, and $3.5 \mathrm{~nm} / \mathrm{s}$ [21] for $\mathrm{SiCl}_{4}$. Moreover, the $\mathrm{Al}$ etching rate with the use of Ar plasma in vacuum was reported to be $\sim 0.025 \mathrm{~nm} / \mathrm{s}$ [25]. The etching rate obtained in our experiment was much higher than the reported values. This difference is due to the fact that the etching in our experiment was caused by streamers whereas etching with chlorine-based gas in vacuum is caused by reactive chlorine. Moreover, the higher etching rate in our experiment than that of vacuum etching with Ar plasma may be caused by the fact that the number of Ar ions that collide with the $\mathrm{Al}$ surface is greater in our experiment than in vacuum etching. Therefore, atmospheric-pressure Ar plasma jet irradiation is consid- ered to be effective for removing $\mathrm{Al}$ from the surface of the glass substrate.

Figure 7 shows thermography images of the $\mathrm{Al}$ thin film during Ar plasma jet irradiation with an irradiation distance of $2 \mathrm{~mm}$. The + mark at the center of the images represents the irradiation spot on the $\mathrm{Al}$ thin film and also the measurement point of temperature. From the figure, the surface temperature of the $\mathrm{Al}$ thin film was $18.2^{\circ} \mathrm{C}$ before irradiation and increased to 21.1 and $21.4{ }^{\circ} \mathrm{C}$ after 1 and $5 \mathrm{~s}$ of irradiation, respectively, which was a slight increase of $3.2{ }^{\circ} \mathrm{C}$. These results confirm that the removal of $\mathrm{Al}$ was not attributed to the heat of the plasma jet. In reverse, the plasma jet irradiation did not thermally damage the glass substrate during the removal of $\mathrm{Al}$.

\section{CONCLUSION}

An atmospheric-pressure Ar plasma jet was generated with a frequency of $10 \mathrm{kHz}$, an applied voltage of $10 \mathrm{kV}$, and an Ar gas flow rate of $10 \mathrm{~L} / \mathrm{min}$. An Al thin film with a thickness of $\sim 3.5 \mu \mathrm{m}$ deposited on a glass substrate was irradiated with the Ar plasma jet in air for $5 \mathrm{~s}$ with irradiation distances of $2-30 \mathrm{~mm}$. After plasma jet irradiation, regions without $\mathrm{Al}$ were observed on the surface of the $\mathrm{Al}$ thin film, indicating that $\mathrm{Al}$ was removed by plasma jet irradiation. The etching rate was $\sim 700 \mathrm{~nm} / \mathrm{s}$. Al was considered to be removed because the streamers in the plasma reached the Al thin film. The shape of the removal marks depended on the irradiation distance: it was disc-shaped with a diameter of $\sim 6 \mathrm{~mm}$ for irradiation distances of 10-20 $\mathrm{mm}$ and ring-shapedwith an inner diameter of $\sim 6 \mathrm{~mm}$ and an outer diameter of $\sim 7 \mathrm{~mm}$ for irradiation distances of 2-7 mm. Thermography observation confirmed that the removal marks were not formed by the heat of the plasma. In reverse, the dependence of the shape of the removal marks on the irradiation distance suggests that the streamers were nonuniformly distributed in the plasma. The streamers inside the quartz tube were seldom observed along the central axis and were concentrated along the inner wall, whereas those outside the tube directly reached the $\mathrm{Al}$ thin film for irradiation distances of 2-7 mm, but for irradiation distances of 10-20 $\mathrm{mm}$, they converged before reaching the Al thin film.

The results of this study indicate that atmosphericpressure Ar plasma jet irradiation is effective for etching Al easily and rapidly. This method is considered to be applicable to the etching of other metals and is expected to be used as a new simple and rapid metal etching method.

\section{ACKNOWLEDGMENTS}

We are grateful to Professor K. Tsuchiya of Tokai University for his cooperation in laser microscopy observation as well as Mr. S. Horie, Mr. T. Tanaka, and Mr. M. Uchino of Photron Limited for their cooperation in high-speed camera observation. 
Coat. Technol. 174-175, 839 (2003).

[3] M. C. Kim, D. K. Song, H. S. Shin, S. -H. Baeg, G. S. Kim, J. -H. Boo, J. G. Han, and S. H. Yang, Surf. Coat. Technol. 171, 312 (2003).

[4] C. H. Yi, Y. H. Lee, and G. Y. Yeom, Surf. Coat. Technol. 171, 237 (2003).

[5] T. Yamamoto, M. Okubo, N. Imai, and Y. Mori, Plasma Chem. Plasma Proc. 24, 1 (2004).

[6] M. Iwasaki, H. Inui, Y. Matsudaira, H. Kano, N. Yoshida, M. Ito, and M. Hori, Appl. Phys. Lett. 92, 081503 (2008).

[7] J. Abenojar, M. A. Martinez, N. Encinas, and F. Velasco, Int. J. Adhes. Adhes. 44, 1 (2013).

[8] S. B. Habib, E. Gonzalez II, and R. F. Hicks, J. Vac. Sci. Technol. A 28, 476 (2010).

[9] D. Skacelova, M. Stupavska, P. St'ahel, M. Cernak, Appl. Surf. Sci. 312, 203 (2014).

[10] S. Kanazawa, M. Kogoma, T. Moriwaki, and S. Okazaki, J. Phys. D: Appl. Phys. 21, 838 (1988).

[11] S. Okazaki and M. Kogoma, J. photopolym. Sci. Technol. 6, 339 (1993).

[12] K. Fricke, H. Steffen, T. von Woedtke, K. Schroder, and K. D. Weltmann, Plasma Process. Polym. 8, 51 (2011).

[13] H. Kuwahata and R. Ohyama, Hyomen Kagaku 30, 174 (2009) [in Japanese].
[14] H. Kuwahata, T. Haraki, and I. Mikami, e-J. Surf. Sci. Nanotech. 11, 36 (2013).

[15] H. Hillborg, J. F. Ankner, U. W. Gedde, G. D. Smith, H. K. Yasuda, and K. Wikstrom, Polymer 41, 6851 (2000).

[16] E. P. T. de Givenchy, S. Amigoni, C. Martin, G. Andrada, L. Caillier, S. Geribaldi, and F. Guittard, Langmuir 25, 6448 (2009).

[17] L. Yang, N. Shirahata, G. Saini, F. Zhang, L. Pei, M. C. Asplund, D. G. Kurth, K. Ariga, K. Sautter, T. Nakanishi, V. Smentkowski, and M. R. Linford, Langmuir 25, 5674 (2009).

[18] R. G. Poulsen, J. Vac. Sci. Technol. 14, 266 (1977).

[19] P. M. Schaible, W. C. Metzger, and J. P. Anderson, J. Vac. Sci. Technol. 15, 334 (1978).

[20] K. Tokunaga, F. C. Redeker, D. A. Danner, and D. W. Hess, J. Electrochem. Sci. 128, 851 (1981).

[21] D. A. Danner, M. Dalvie, and D. W. Hess, J. Electrochem. Sci. 134, 669 (1987).

[22] S. C. McNevin, J. Vac. Sci. Technol. B 8, 1212 (1990).

[23] R. Ohyama and A. Nagai, Japan Patent, 244938 (2006).

[24] H. Kuwahata and T. Yamaguchi, e-J. Surf. Sci. Nanotech. 13, 474 (2015).

[25] J. W. Coburn and H. F. Winters, J. Appl. Phys. 50, 3189 (1979). 